\section{SOCIETY OF AGRICULTURAL BACTERIOLOGISTS}

$\mathrm{T}$ HE annual conference of the Society of Agricultural Bacteriologists, held at the University of Leeds during August 27-29, 1942, reflected the influence of war-time conditions. Several members of the Society were unable to leave their duties in order to attend the conference, and the papers, particularly those concerned with dairying, showed that problems of immediate practical importance are being investigated. The field covered by the discussions was nevertheless wide and afforded an index of the activities of a society which exists with the object of advancing the study of general, agricultural and related branches of bacteriology.

A contribution to the bacteriology of sewage disposal dealt with the nitrifying activity of biological film from percolating filters. The activity was measured by inoculating an ammonium sulphatecalcium carbonate solution with a dilute suspension of film, aerating the cultures in inverted conical flasks, and determining the rate of production of nitrite and nitrate. Nitrifying activity was found to be influenced by season, depth below the surface of the filter and the rate of treatment of sewage. Film produced in ordinary single filtration acted differently from film obtained in the process of alternating double filtration, in which two filters are operated in series with a periodic change in the order of flow.

In the disposal of certain industrial wastes the activity of the sulphate-reducing organism Vibrio desulphuricans may require control. It has been shown that this microbe may be easily suppressed by the relatively simple and inexpensive method of adjusting the hydrogen ion concentration to less than $p \mathrm{H} 5$ or more than $p \mathrm{H} 10$. An illustration of the practical application of this principle was cited. A pond used for the reception of a waste containing 20-30 per cent of fatty matter and 3-4 per cent of sulphate (as calcium sulphate), at the rate of about forty tons a week, created a nuisance in the locality owing to the evolution of hydrogen sulphide. The $p H$ value of the water was brought to 3 by adding sulphuric acid and the trouble was eliminated.

Shellfish which have been subjected to the process of self-purification in tanks of clean sea water have recently provided a problem. On arrival at inland markets they sporadically harbour large numbers of coliform organisms, and the suspicion that purification has been inadequate naturally arises. Investigation showed, however, that this occurrence is due to multiplication during transport of coliform bacilli which have no sanitary significance. With the object of finding a rapid method which would differentiate typical Bacterium coli from other members of the group the modification of the Eijkman test using MacConkey's broth was re-investigated. Taking the production of acid and gas as the differential criterion, an incubation temperature of exactly $44^{\circ} \mathrm{C}$. afforded the best separation of the types. In an examination of 1881 cultures derived from a variety of sources, 97.5 per cent of the typical $B$. coli produced acid and gas at $44^{\circ}$ and only $5 \cdot 2$ per cent of the other coliform strains did so.

The coliform group in its relation to dairy products was also discussed. It has been found that the presumptive test for the presence of these organisms when applied to milk gives a lower estimate of the coliform population than when applied to water.
Abnormal gas formation in factory-made Cheddar cheese was attributed to coliform bacilli introduced into pasteurized cheese milk from such sources as coolers and pipe lines. While various types of this group were isolated, typical $B$. coli predominated at all stages in the making and ripening of the cheese examined and appeared to be responsible for the majority of cases of gas production.

Bacteriophage active against streptococci, which may be responsible for difficulties in the making of Cheddar cheese, has now been successfully demonstrated in high dilutions prepared from cheese up to $3 \frac{1}{2}$ months old.

The resazurin reduction test is receiving much attention as a means of grading milk. One paper described the chemistry of resazurin and gave practical hints on the test. Other two papers dealt with the 10 -minute resazurin test which is now used for the rapid recognition of unsatisfactory milk, a product which has become an important problem under war-time conditions. According to the colour of the milk-dye mixture after 10 minutes at $37^{\circ} \mathrm{C}$. milk may be classified in three categories: (1) suitable for the liquid milk market, (2) suitable for manufacture only, and (3) unacceptable for any purpose. The results usually agree with those of methylene blue reduction and are obtained in a shorter time. Other rapid tests, such as those utilizing titratable acidity, $p \mathrm{H}$, clot formation on boiling, alcohol precipitation, smell and taste, have been found to be less suitable for use on the receiving platform of creameries. A fourth paper presented evidence that the resazurin test, when performed at $18^{\circ} \mathrm{C}$., gives within two hours a reliable indication of the keeping quality of milk. Samples of really poor keeping quality can be detected within 30 minutes by the $18^{\circ}$ test.

Mastitis of the dairy cow was discussed in three contributions. A comparison of diagnostic methods applied to a large number of samples led to the conclusion that for the detection of sub-clinical mastitis a combination of two indirect tests, the determination of the leucocyte content and of the electrical conductivity of milk, is superior to the isolation and identification of the infecting organism in reliability, speed and cost of materials. Milk from an infected quarter has an abnormally high cell count and, largely owing to an excess of chlorides, a high conductivity. The standards adopted to differentiate between normal and infected milk were 500,000 cells per $\mathrm{ml}$. and a conductivity of $49 \cdot 0 \times 10^{-4}$ mhos.

In the second paper on mastitis, which described field observations on the control of the disease, methods of cultivating Streptococcus agalactioe were compared, and evidence was presented to show that factors such as unsuitable milking machines have an important influence in raising the infection rate. The third paper dealing with mastitis described a broth containing peptone, yeastrel, mannitol, æsculin and hippurate which permits $S$. agalactioe to display the majority of its differential characters. It is thus possible to identify the organism by preparing a single culture in the composite medium.

Other contributions to the proceedings dealt with methods of increasing the heat resistance of the spores of a putrefactive anærobe and with the control of moulds (Penicillium and Mucor) in meat pies by changing the methods of manufacture.

In spite of difficulties due to the War, this conference was most successful and did not depart from the trend towards greater variety of interests which has characterized annual meetings of the Society. 